POLLACK PERIODICA

An International Journal for Engineering and Information Sciences

DOI: $10.1556 / 606.2016 .11 .1 .14$

Vol. 11, No. 1, pp. 157-161 (2016)

www.akademiai.com

\title{
SUSTAINABLE DEVELOPMENT OF THE TOWN CENTER OF VISEGRÁD
}

\author{
Krisztián KOVÁCS-ANDOR \\ Department of Architectural Design, Faculty of Engineering and Information Technology, \\ University of Pécs, Rókus u. 2, H-7624 Pécs, Hungary \\ e-mail: kovacs.andor.pollack@gmail.com
}

Received 11 March 2015; accepted 26 October 2015

\begin{abstract}
Visegrád, with its 1800 inhabitants, is considered to be the smallest town of Hungary. The development of the town center is a fine example for how the original exaggerating ideas were altered due to the economic crisis - besides its negative effects - and facilitated the birth of a sustainable development, satisfying the continuous needs of the local community and the temporary demands of tourism.
\end{abstract}

Keywords: Urban development, Sustainability, Sustainable development, Public spaces, Local community

\section{Introduction}

Visegrád is a thousand-year-old settlement, formerly used as royal residency; however the town today is rather rustic in terms of its scale and buildings. In 2000, after acquiring the town status, the settlement undertook a monumental mission, compared to its size. At the place of the supposed medieval town's main square, a plan was put out to competition to build a new town center. In 2008, as the winners of the previously mentioned competition, the architectural office, called A+ Építész Stúdió (designers: Anna Mária Tamás and Krisztián Kovács-Andor) began to design the town center, town hall, saloon, cultural center, a new main square and other public spaces. However, in the next few years the emergence of the economic crisis overwrote the original ideas and required the revision of the design program. Considering sustainability and costeffectiveness the development of the town center took a new direction. The design program was completely redefined, which put the emphasis on the utilization of the 
existing and idle buildings. Moreover modernization, refurbishment and expansion were major concerns with a low number of new constructions. The only entirely new element is the events hall.

\section{Programme}

The events hall can be found at the place of the town hall, designed originally, in the façade of the medieval German town's main square. Its role, on the one hand is to provide a face for the town center with being a gate towards the Danube, on the other hand it creates connection between the big and the small events squares. The building can be opened into blade walls; with its 'disappearing' gates it is able to serve one and the other, in case of grand events, both. Its events square - open or closed - is suitable for organizing exhibitions, presentations, receptions and craft markets.

The paneling extension of the Health-house's façade is the contemporary transcript of the ornate wooden pediments of the houses in the Main Street overlooking the Danube. Its actual function is an outdoor covered-open loft ladder; however its main role is to form the facade of the Health-house towards the events square and the Danube (Fig. 1).

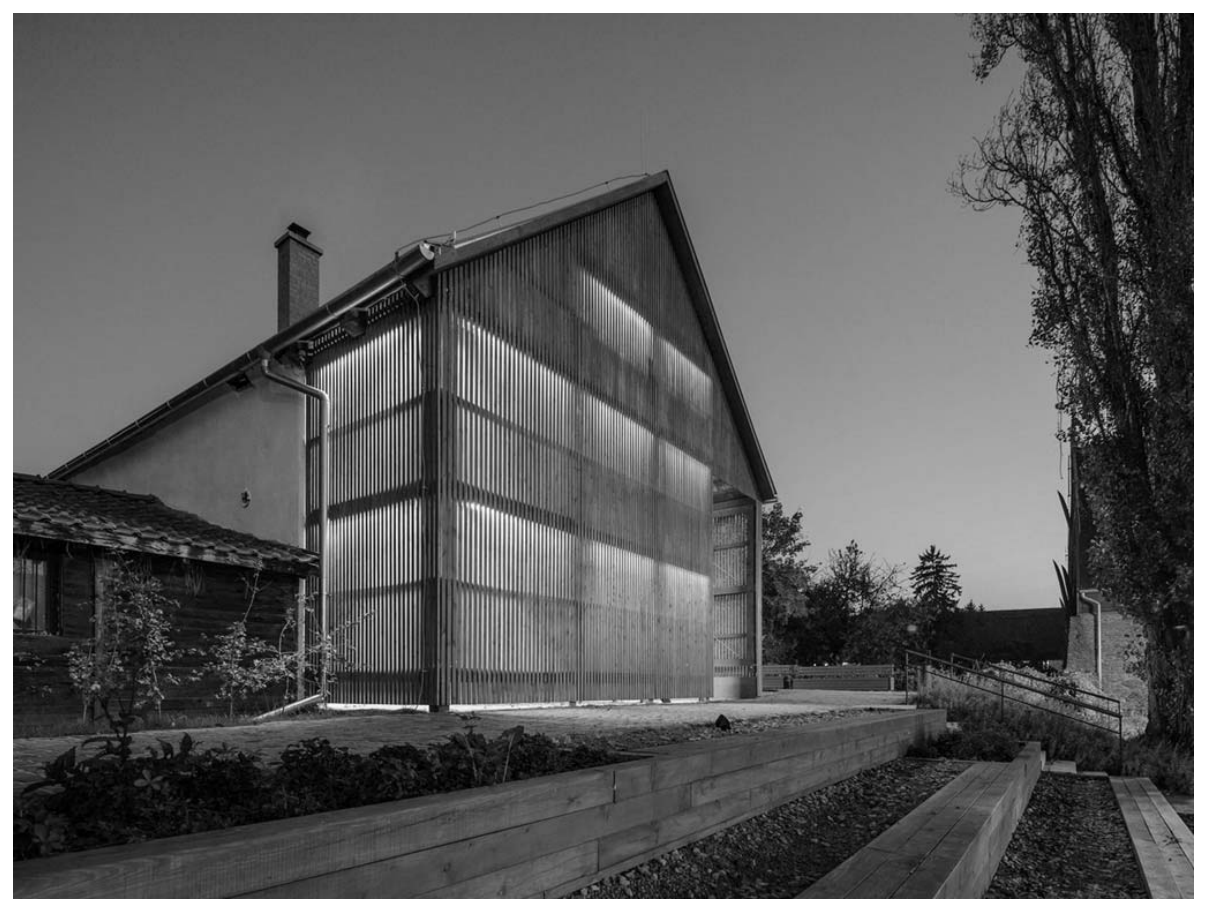

Fig. 1. The paneling extension of the Health-house 
The refurbishment of the public spaces is adjusted to the current and real needs of the town. As part of the public spaces program, the yard of the Health-house was formed which is used as a bio market at the weekends. The smaller events square between the events buildings and the Health-house is suitable for organizing minor town programs, a public square calibrated to the size of a small town. The bigger grassy space, facing the Danube, comes alive at the time of the internationally-known Palace Games (Fig. 2).

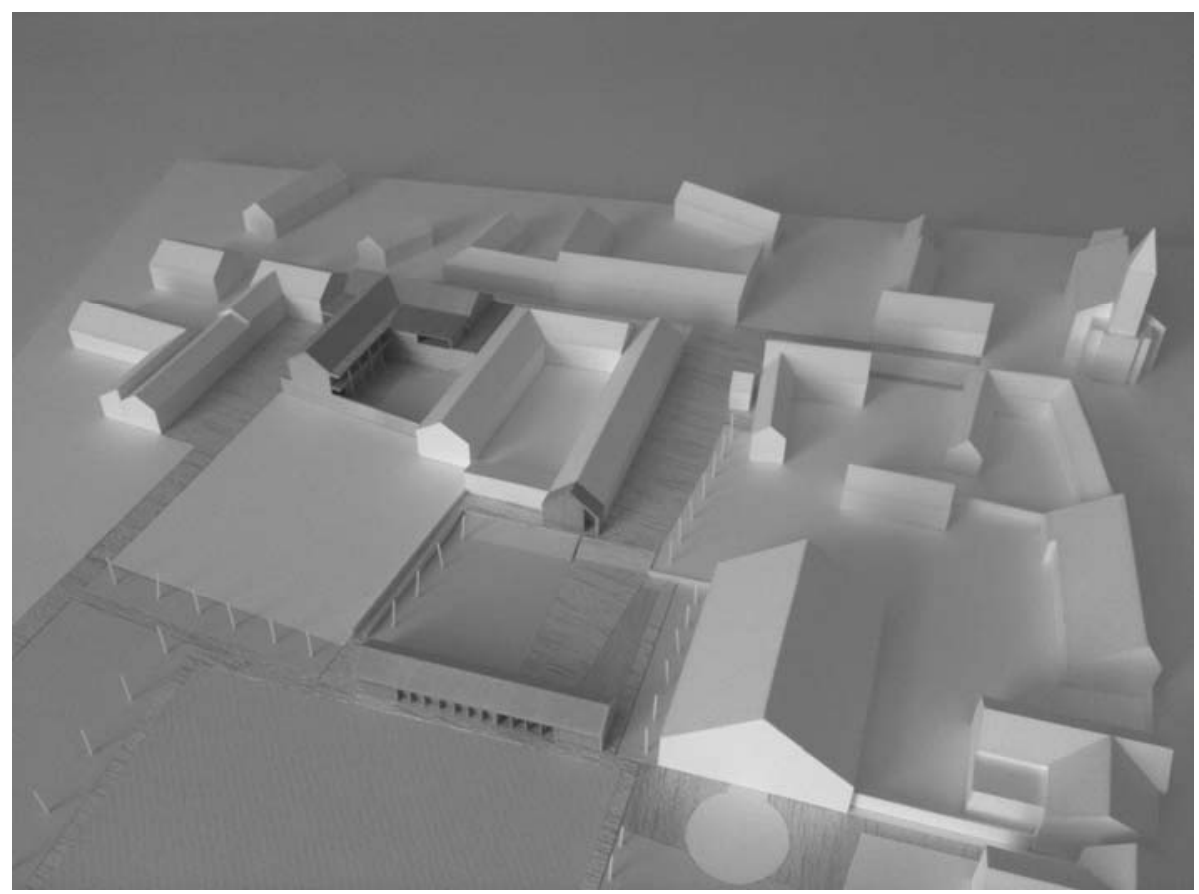

Fig. 2. Architectural model of the new town center with the new public spaces

\section{Object-like design}

Due to the complex situation, the building was formed not as a new, house-like element of the town, but rather an object-like gesture of the complete landscape. The choice of structure and materials, the definition of the interior and exterior spaces, and the connections among all these were considered as its two tools. The connection between the exterior and interior spaces comes into being in a non-traditional way, by means of windows and doors. The openings on the building serve the object-like state of the house. The building is mainly a transitional space. On the one hand it is a coveredopened shed functioning as a gate-motif, on the other hand it is an events square being able to be differentially open and closed with the other spaces (Fig. 3, Fig. 4). 


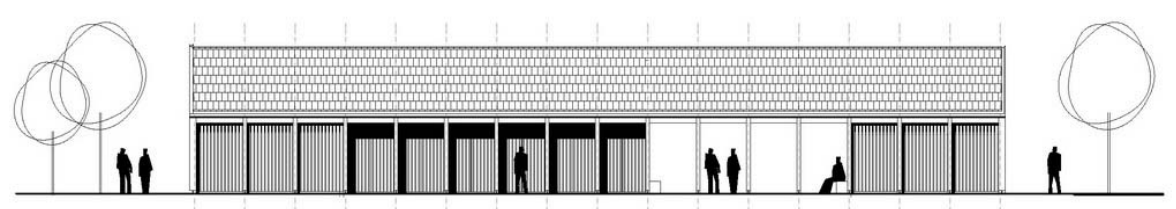

Fig. 3. The west elevation of the event building

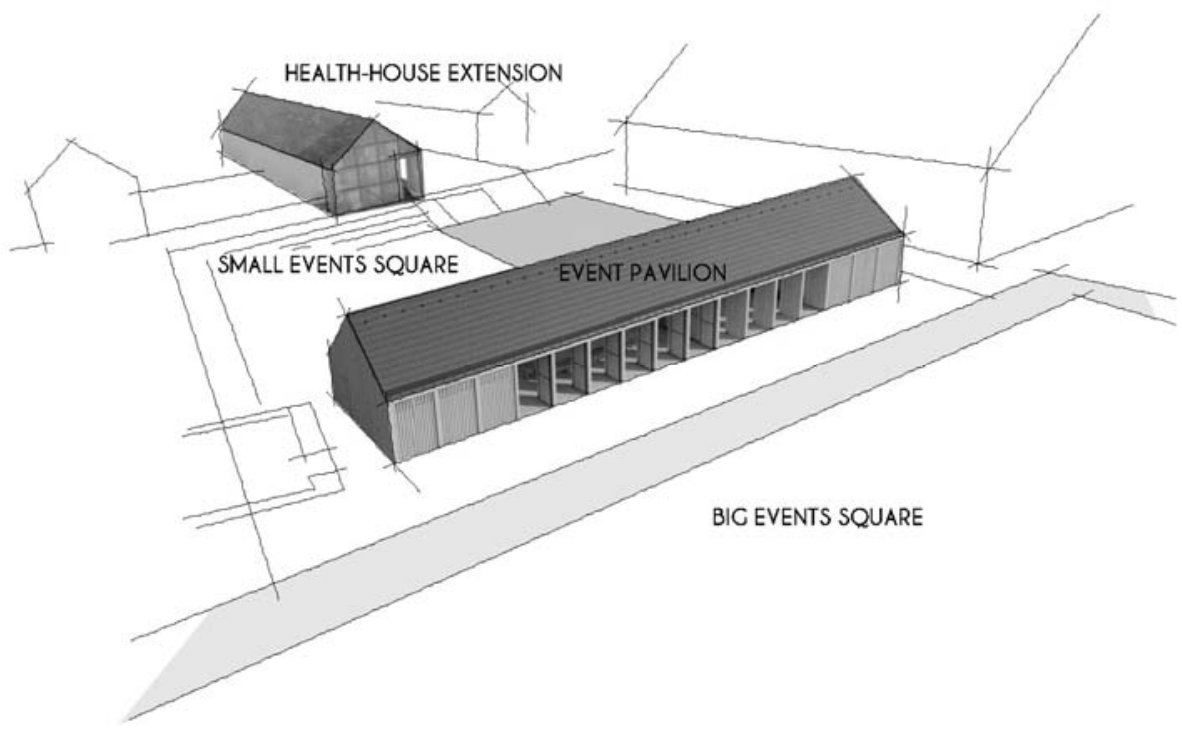

Fig. 4. The covered-opened mass of the event building between the public squares

\section{Provisionality and sustainability}

The building functions as a secondary façade, as a membrane, and in certain cases it is transformable. In order to have this quality, wood was chosen as a primary structural and covering material. Wood possesses the features, which meant solution for the problems arose. Natural, local and traditional building material, which also ages fairly and it is alterable, if necessary it can be 'eliminated' without any problem. In terms of sustainability, it is also a fine choice in connection with the entire lifecycle of the building. 
Beyond the previously mentioned, sustainability meant technologies that can be available also for craftsmen being present in the local community. The building was furnished with individually designed and locally made furniture. It was a crucial aspect to form spaces that can be used in a differentiated way by the constantly changing community and by means of changing the needs it can easily be transformable. It was also essential to minimize demands and spaces and create functions with using the minimum amount of space and materials (Fig. 5).

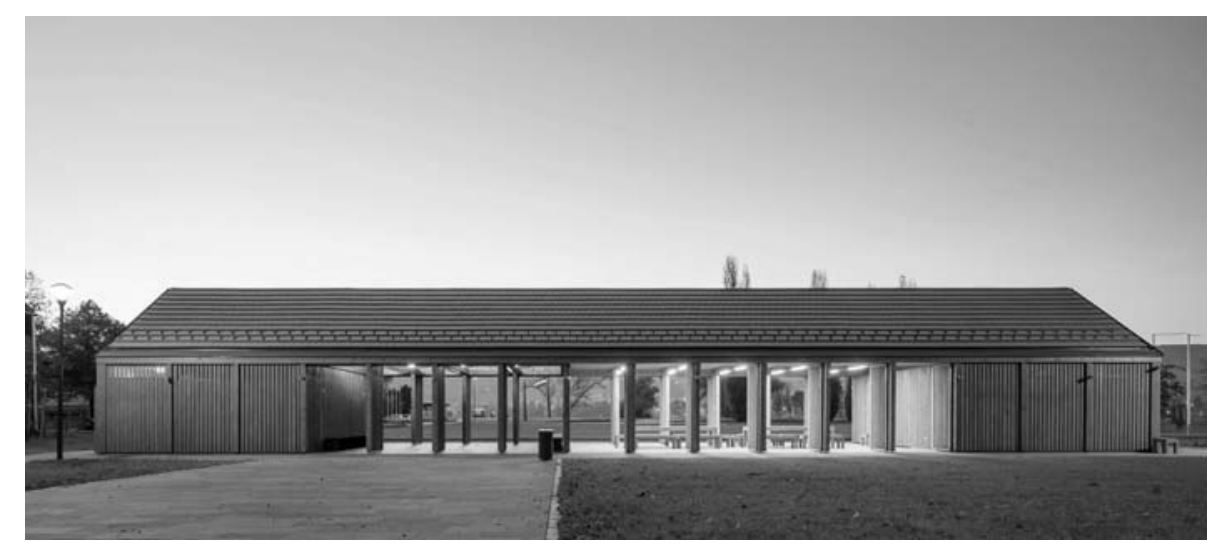

Fig. 5. The gate-like mass of the event building

\section{Local communities and tourists}

In Visegrád there is an active community with strong identity, where participation is easier due to the scale of the settlement, and it can also be observed in the change of the design program. On the other hand, the target audience is an even more considerable layer consists of Hungarian and foreign tourists. The building is eager to satisfy the everyday needs of the inhabitants and in tandem with that, it is able to serve vast crowds at temporary programs as well.

\section{Conclusions}

'Less is more.' The world famous sentence of Mies van der Rohe, one of the most well-known architects of the $20^{\text {th }}$ century, is completely true in this case. The development of the town center of Visegrád proves that the economic crisis - besides its negative effects - can help to rethink the conventional attitude, and consider the urban development as a possibility to create sustainable frames for the public life. After a 6year-long designing process in Visegrád the original exaggerating ideas were altered which facilitated the birth of a sustainable development, satisfying the continuous needs of the local community and the temporary demands of tourism. 